LÓPEZ RIOPEDRE, J., «Trabajo sexual transnacional: consecuencias de las políticas criminalizadoras de la prostitución y de la crisis económica española sobre las trabajadoras sexuales migrantes», REDUR I4, diciembre 20ı6, págs. 67-86. ISSN i695-078X

\title{
TRABAJO SEXUAL TRANSNACIONAL: CONSECUENCIAS DE LAS POLÍTICAS CRIMINALIZADORAS DE LA PROSTITUCIÓN Y DE LA CRISIS ECONÓMICA ESPAÑOLA SOBRE LAS TRABAJADORAS SEXUALES MIGRANTES
}

\author{
José LÓPEZ RIOPEDRE \\ DOCTOR EN SOCIOLOGÍA \\ UNIVERSIDAD NACIONAL DE EDUCACIÓN A DisTANCIA
}

SUMARIO: I. Introducción. II. Marco teórico-metodológico. III. Redes informales y cultura migratoria. IV. Criminalización y movilidad. V. Efectos de la crisis económica en la prostitución. VI. Un futuro incierto. Nuevos retos. VII. Bibliografía.

RESUMEN: El intenso flujo migratorio que ha caracterizado a la industria del sexo europea durante las últimas dos décadas se ha visto recientemente afectado por la grave crisis económica que sufren algunos países como España. En este sentido, muchas migrantes extracomunitarias con permiso de residencia español se están desplazando cada vez más a otros países de la Unión Europea como Francia, Suiza, Reino Unido, Italia o Alemania, ampliando de esta forma su campo de acción (desempeño de plazas) para el ejercicio de la prostitución. Esta tendencia hacia una mayor movilidad de las migrantes se puede perfectamente contextualizar a partir del propio dinamismo de la industria del sexo en un mercado capitalista globalizado. Aún así, contrasta el hecho de que, con frecuencia, las migrantes viajen a lugares donde la prostitución se halla ampliamente criminalizada y perseguida, exponiéndose a sufrir las consecuencias de la violencia institucional. Es el caso, por ejemplo, de las migrantes latinoamericanas residentes en nuestro país que actualmente se dirigen desde España a Francia para trabajar allí. La existencia de un ordenamiento jurídico europeo muy contradictorio en torno a esta cuestión, a pesar de que el modelo sueco (abolicionismo radical) se está imponiendo en el resto de Estados de la Unión, dificulta mucho el estatus ciudadano de estas migrantes, oscilando su condición jurídica entre el rol de «víctima» y el de migrante «irregular». Al mismo tiempo, otros colectivos de migrantes se van sucediendo en la industria del sexo nacional en función de variables de carácter socio-estructural. Este trabajo pretende abordar estos movimientos migratorios, al margen del excesivamente manido enfoque trafiquista, y reparando, en cambio, en las causas/consecuencias de los fenómenos apuntados.

PALABRAS ClaVE: Trabajo sexual, migraciones, transnacionalidad, criminalización, crisis económica

ABSTRACT: The intense migratory flow that has characterized the European Sex Industry during the last two decades has recently been affected by the severe economic crisis facing countries like Spain. In this regard, many non-EU migrants with Spanish residence permit are increasingly shifting to other EU countries such as France, Switzerland, United Kingdom, Italy and Germany, thus expanding its scope (performance plazas) for the exercice of prostitution. This trend towards greater mobility of migrants can be perfectly contextualize from dynamism of the Sex Industry in a globalized capitalist market. Still, contrasts that often migrants traveling to places where prostitution is criminalized and persecuted widely, exposing themselves to suffer the consequences of State Violence. This applies, for example, Latin American migrants living in our country currently directed from Spain to France to work there. The existence of a very contradictory European Law around this issue, although the Swedish model (radical abolitionism) is prevailing in other States of the EU, makes it very difficult citizenship status of these migrants, swinging her legal condition between the role of «victim» and «irregular» migrant. At the same time, other groups of migrants are replacing on the national Sex Industry based on social and structural variables. This paper aims to address these movements, regardless of the traffic approach too trite, and repairing, however, the causes/consequences of the phenomena targeted.

KEYWORDS: Sex work, migration, transnationality, criminalization, economic crisis 


\section{Introducción}

El carácter transnacional del trabajo sexual ${ }^{1}$ es una realidad inherente al propio dinamismo observado en la industria del sexo durante las últimas dos décadas en el marco de la globalización capitalista, donde se insertan en el mercado todo el elenco de servicios profesionales de cuidado, afectivos y sexuales a terceros. Estudiosos de la dinámica de los mercados del sexo definen la transnacionalidad en este contexto como aquellos procesos a través de los cuales las personas cruzan las fronteras con el fin de ofrecer y consumir servicios sexuales, estableciendo relaciones complejas en diferentes lugares ${ }^{2}$. Partiendo de esta premisa, y lejos de la visión esencialista y hegemónica de la prostitución derivada del paradigma trafiquista ${ }^{3}$ donde el discurso de la violencia de género y de la trata y la explotación sexual despojan hoy sistemáticamente a las trabajadoras sexuales migrantes de su capacidad de agencia, con este trabajo pretendo mostrar que los más recientes flujos migratorios de mujeres, hombres y transgéneros hacia la industria del sexo obedecen con frecuencia a auténticas estrategias de movilidad social ascendente e incluso emancipadoras ${ }^{4}$ llevadas a cabo por las propias migrantes y que pueden acompañar a otras causas socioestructurales más profundas y subyacentes, pero en cualquier caso sin que estas últimas deriven en un fatal determinismo etiológico como se argumenta insistentemente a partir de las posturas neo-abolicionistas 5 .

Al superar la perspectiva teórica dominante que articula la llegada de inmigrantes en el marco de un proceso de migración forzoso y/o coactivo auspiciado por el crimen organizado y colocar, en cambio, sobre la mesa la heterogeneidad de proyectos y estrategias migratorias de todos los agentes sociales, se amplifica nuestra mirada acerca de la realidad de un fenómeno migratorio complejo como el que pretendemos abordar. Un primer paso

\footnotetext{
I Con la expresión trabajo sexual me refiero en todo momento al ejercicio de la prostitución de forma libre y consciente, quedando así al margen las situaciones de esclavitud sexual y los circuitos para la trata de personas que no son objeto de análisis para este estudio. Aclarado este punto, debo añadir también que el trabajo sexual, al igual que cualquier otro tipo de trabajo, puede desempeñarse en una gran diversidad de condiciones, oscilando éstas desde la precariedad más absoluta y el abuso por parte de empresarios y/o intermediarios al desempeño en condiciones óptimas con la obtención de grandes beneficios económicos para las trabajadoras.

2 Agustín, Laura, Sexo y marginalidad. Emigración, mercado de trabajo e industria del rescate, Madrid, Editorial Popular, 2009; Piscitelli, Adriana, Trânsitos: brasileiras nos mercados transnacionais do sexo, Rio de Janeiro, Universidade Estatal do Rio de Janeiro, 2013

3 Tomo esta expresión de AzIzE, «Empujar las fronteras: mujeres y migración internacional desde América Latina y el Caribe» en Osborne (ed.), Trabajador@s del sexo. Derechos, migraciones y tráfico en el siglo XXI, Barcelona, Bellaterra, 2004. La autora se refiere al enfoque trafiquista como la visión que utilizan los medios de comunicación y las agencias internacionales para mostrar las migraciones como una consecuencia de la acción del crimen organizado, sin tener en cuenta la realidad de la migración autónoma.

$4 \mathrm{Al}$ margen del carácter transgresor que puede suponer en algunos casos el desempeño del trabajo sexual desde la posición de una trayectoria disidente, me estoy refiriendo aquí más bien a la emancipación como ruptura y superación de las barreras patriarcales, de pobreza y constreñimiento social que oprimen muchas veces a las mujeres en sus lugares de origen y que las lleva a consolidar sus proyectos migratorios en destino. Véase, en este sentido el trabajo de AlCAldE, «Cosas de mujeres: familias monoparentales dominicanas en Barcelona y Nueva York», Revista Internacional de Organizaciones, nffl 6, 20II, págs. Io9-I34, con migrantes dominicanas en Barcelona y Nueva York.

5 Para una crítica sistematizada de las posiciones abolicionistas a partir de un conjunto de resultados empíricos, véase Solana y Riopedre, Trabajando en la prostitución. Doce relatos de vida, Granada, Comares, 2012.
} 
en este trayecto será intentar dejar atrás muchos de los prejuicios y valoraciones morales que por lo común empleamos al tratar el tema de la prostitución. A continuación, deberemos de hacer un esfuerzo por incorporar el discurso de las migrantes al debate y análisis teórico, desechando la victimización, y procurando un equilibrio con los resultados empíricos de nuestras investigaciones sociales. A partir de ahí podremos entonces hacer un mejor uso de interesantes herramientas teóricas como las redes informales o la cultura migratoria que nos ayudarán a obtener una visión más amplia, profundizando en la gestación de los proyectos de las migrantes, en las estrategias individuales y familiares de movilidad social, la diversidad de circunstancias concurrentes en la inserción en la industria del sexo, la complejidad de las causas, la movilidad social intra-sectorial, la constitución de cadenas migratorias o la redefinición del propio proyecto migratorio. Todo esto nos conducirá a observar la realidad de la prostitución en clave de trabajo sexual transnacional, en su constante evolución y dinamismo, enfrentándose a las propias contradicciones internas y al constreñimiento jurídico-político externo a la vez que viendo cómo procura adaptarse a las actuales circunstancias económicas y sociales en la era de la globalización.

La reivindicación de esta idea de las trabajadoras sexuales migrantes como agentes sociales constructores de su propia historia no es nueva, como lo es menos aún la defensa del papel activo de los migrantes en general. Así, y siguiendo a RAMíREZ: «El concepto de inmigrante que aquí manejamos es el de sujeto activo (actor social) que teoriza (interpreta) y practica sobre lo que vive, cómo y por qué lo vive, que asigna e intercambia sentidos con sus otros, que dispone de cierto margen de maniobra y decisión en determinadas esferas de su vida, que no es un mero reproductor pasivo de las sobredeterminaciones políticas y económicas que le imponen su situación» ${ }^{6}$. El reto, aquí sería contextualizar debidamente a las trabajadoras sexuales migrantes en la actual dinámica aparentemente contradictoria entre el auge de las políticas criminalizadoras de la prostitución y el incremento observado de la movilidad transnacional de esas mismas migrantes.

En los actuales estudios sobre migraciones transnacionales la mayoría de las veces las trabajadoras sexuales permanecen en la invisibilidad, y no se les atribuye el merecido papel activo de actores sociales al quedar abducidas por el paradigma de la victimización7. Esto ha levantado sendas críticas en relación con las trabajadoras sexuales que actúan efectivamente como jefas de hogar y que «optan por la migración como una estrategia de mantenimiento del hogar transnacional» ${ }^{8}$ y por extensión hacia todas aquellas concepciones reduccionistas del carácter transnacional de los movimientos migratorios que no tienen en

\footnotetext{
${ }^{6}$ Ramírez, Eugenia, Etnicidad, identidad y migraciones, Madrid, Ramón Areces, 2007, pág. 457

7 Esto no ocurre sólo en el caso de las trabajadoras sexuales, sino que también sucede con las migrantes que se ocupan en el servicio doméstico y otras actividades marginales. Véanse, en este sentido, los estudios de NYBERG («Migración, género y desarrollo: el caso dominicano» en Zúñiga (cord.), La migración, un camino entre el desarrollo y la cooperación, Madrid, Centro de Investigaciones para la Paz, 2005, págs. I63-I82) sobre migrantes dominicanas empleadas en el servicio doméstico y de BETRISEY («Migración y trata de personas para la explotación laboral en talleres textiles de la ciudad de Buenos Aires-Argentina- Génesis social y política bajo el proyecto económico neoliberal», Latin American Perspective, 20I4) con migrantes bolivianos ocupados en los talleres textiles.

8 Oso, Laura, La migración hacia España de mujeres jefas de hogar, Madrid, Ministerio de Trabajo y Asuntos Sociales, Instituto de la Mujer, 1998
} 
cuenta valores como la circulación de remesas económicas y otros bienes inmateriales entre diferentes países ${ }^{9}$. Las trabajadoras sexuales migrantes son, por derecho propio, migrantes transnacionales que cuentan con una cultura migratoria y que hacen uso constante de redes de apoyo durante sus desplazamientos, manteniendo un estrecho contacto con el núcleo familiar en sus países de origen y en sus principales lugares de destino en el caso de nuevos cruces de fronteras, utilizando las nuevas tecnologías, los intercambios y la ampliación de proyectos vitales en la acción de su «múltiple presencia» ${ }^{\circ}$, adaptándose a la dinámica y avatares de una industria del sexo global y desempeñando diferentes roles en la singularidad del espacio transnacional.

\section{Marco teórico-metodológico}

Durante mis investigaciones acerca de las dinámicas de la industria del sexo y los movimientos migratorios he venido apuntando hacia una experiencia etnográfica global, donde el trabajo de campo se ha dilatado en el tiempo, a la vez que se ha des-localizado, principalmente entre España, Brasil y Rumanía, en lo que algunos ya han descrito antes como etnografía multi-situada ${ }^{\text {II }}$ y que yo he preferido transformar más bien en un particular biograma sobre los mercados del sexo donde las principales protagonistas son las trabajadoras sexuales, y cuya perspectiva emic he intentado integrar a partir de la construcción de redes de convivencia e intimidad con los actores sociales, amalgama viva y activa de la que surgirán luego relatos biográficos e historias de vida. A lo largo de este tránsito teórico-metodológico he osado también reconocerme en los enfoques de brillantes investigadoras como AGUSTín o PISCITELLII ${ }^{\text {I2 }}$ que rehúyen de cualquier signo de esencialismo y enfatizan la complejidad de los procesos migratorios. Es desde esta perspectiva que las dimensiones de análisis conjugan los condicionamientos espaciotemporales con los distintos procesos estructurales convergentes en la globalización, las redes sociales y la cualidad de agentes activos de las migrantes como protagonistas que generan su propio discurso. Otras contribuciones teóricas más específicas en el campo del transnacionalismo como las de Oso, PORTES, ONG o GLICK SCHILLER ${ }^{\mathrm{I3}}$ me han ayudado

9 Pisctitelli, Adriana, «Brasileiras na indústria transnacional do sexo. Migraçôes, direitos humanos e antropología», Nuevo Mundo Mundos Nuevos, 7, Sección Debates, 2007; Riopedre, José, Inmigración colombiana y brasileña y prostitución femenina en la ciudad de Lugo: Historias de vida de mujeres que ejercen la prostitución en pisos de contactos, Tesis doctoral, departamento de Sociología I, Facultad de Ciencias Políticas y Sociología, UNED, 2010

Io RiBAS, Natalia, «Todo por la familia. La emigración de las familias desde el origen» en Checa y Olmos (eds.), Mujeres en el camino. El fenómeno de la migración femenina en España, Barcelona, Icaria, 2005, págs. IO5-II5

II MARCuS, George, «Ethnography in/of the World System: the Emergence of Multi-sited Ethnography», Annual Review of Anthropology, n. 24, I995, págs. 95-II7

I2 Agustín, Laura, Trabajar en la industria del sexo y otros tópicos migratorios, San Sebastián, Gakoa, 2004; Pisctitelli, Adriana, «Brasileiras na indústria transnacional do sexo. Migraçôes, direitos humanos e antropología», Nuevo Mundo Mundos Nuevos, 7, Sección Debates, 2007; PISCiTelli, Adriana, Trânsitos: brasileiras nos mercados transnacionais do sexo, Rio de Janeiro, Universidade Estatal do Rio de Janeiro, 20I3

I3 Oso, Laura, La migración hacia España de mujeres jefas de hogar, Madrid, Ministerio de Trabajo y Asuntos Sociales, Instituto de la Mujer, I998; PoRTES, Alejandro, Globalization from Below: The Rise of Transnational Communities, Princeton University, I997; ONG, Aihwa, Flexible Citizenship, the Cultural Logics 
asimismo en la comprensión de estos procesos. Por otro lado, mi actual concepción de la sexualidad se ha ido construyendo en el tiempo de la mano del post-estructuralismo de Foucault, de teóricas queer y de importantes aportaciones desde el campo de la antropología de la sexualidad ${ }^{14}$ y de la sociología interaccionista. En particular, algunas herramientas teóricas como el pánico moral ${ }^{15}$, la sexualidad conducente ${ }^{\mathrm{T}}$ o la afiliación dionisíaca ${ }^{\mathrm{T7}}$ son acreedoras de mi principal línea argumental acerca de la criminalización de la prostitución y los procesos de victimización. Mi relación personal con algunas de estas personas ha sido además un regalo del cielo que me ha permitido mantener vivo el diálogo académico, la colaboración activa y el intercambio de informaciones. Especialmente agradecido en este sentido me siento también con la Fundación Carolina que me otorgó una beca en 2012 como profesor visitante en el Núcleo de Estudos de Gênero-Pagu en la UNICAMP/Sâo Paulo, centro de investigación pionero a nivel mundial en cuanto a investigación social de los mercados del sexo, migración y tráfico de personas, brindándome así la oportunidad de conocer de primera mano el muy interesante trabajo de investigación social que allí se está desarrollando, al margen de poder continuar con mi trabajo de campo en ese país.

Los datos que articulan este trabajo proceden de varias de mis investigaciones realizadas durante las últimas décadas con trabajadoras sexuales migrantes ${ }^{18}$ y cuyos resultados he venido a comparar con otros estudios recientes sobre mercados del sexo y migraciones transnacionales ${ }^{\mathrm{I}}$, construyendo de esta forma un amplio material empírico

of Transnationality, Durham, Duke University Press, I999; GLICK SCHILlER, Nina; BASCH, Linda y SzANTON, Cristina, «De inmigrante a transmigrante: aproximación teórica de la migración transnacional» en Sánchez (ed.), La Etnografía y sus aplicaciones. Lecturas desde la Antropología social y cultural, Madrid, Ramón Areces, 2009, págs. 325-354

I4 VANCE, Carole, «El placer y el peligro: hacia una política de la sexualidad» en Vance (comp.), Placer y peligro. Explorando la sexualidad femenina, Madrid, Talasa, I989, págs. 9-49; Rubin, Gayle, «Reflexionando sobre el sexo: notas para una teoría radical de la sexualidad» en Vance (comp.), Placer y peligro. Explorando la sexualidad femenina, Madrid, Talasa, I989, págs. Iı3-I90; Nieto, José A., Sociodiversidad y sexualidad, Madrid, Talasa, 20II.

I5 Cohen, Stanley, Folk Devils and Moral Panics, London and New York, Routledge, 20II/ v.o. I972

${ }^{16}$ Nieto, José A., Sociodiversidad y sexualidad, Madrid, Talasa, 20 II

I7 Riopedre, José, Mujeres cruzando el Atlántico. Relatos biográficos de migrantes brasileñas en los mercados del sexo, Granada, Comares, 2015

I8 RIOPEDRE, José, Mara y sus amigas, Lugo, Manuscritos, 2004; Riopedre, José, Inmigración colombiana y brasileña y prostitución femenina en la ciudad de Lugo: Historias de vida de mujeres que ejercen la prostitución en pisos de contactos, Tesis doctoral, departamento de Sociología I, Facultad de Ciencias Políticas y Sociología, UNED, 2OIO; RIOPEDRE, José, «La criminalización de la industria del sexo, una apuesta políticamente correcta», Gazeta de Antropología, nffl 27/2, 20II; RiOPEDRE, José, «Situación presente de la prostitución en el contexto gallego (2000/II) » en Iglesias y Puente (coords.), Sistema penal y perspectiva de género: trabajo sexual y trata de personas, Granada, Comares, 20I2, págs.I2I-I55; RIOPEDRE, José, «La figura del mediador en el mercado del sexo: cafetinas brasileras, traductoras francesas y peste rumano», VIII Congreso sobre Migraciones Internacionales en España, Granada, setiembre 20I5; Riopedre, José, Mujeres cruzando el Atlántico. Relatos biográficos de migrantes brasileñas en los mercados del sexo, Granada, Comares, 2015

I9 TeIXeIRA, Flávia, «L'Italia dei Divieti: entre o sonho de ser européia e o babado da prostituiçâo», Cadernos pagu (3I) 2008, UNICAMP, 2008, págs. 275-308; HURTADO, Teodora, Mujeres, Negras e Inmigrantes construyendo la ocupación de «proveedoras» de servicios afectivos y «vendedoras» de bienes erótico-amorosos en los espacios transnacionales, Tesis doctoral, México, Universidad Autónoma Metropolitana, División de Ciencias Sociales y Humanidades, 20Iı; PISCITELli, Adriana, Trânsitos: brasileiras nos mercados transnacionais do sexo, Rio de Janeiro, Universidade Estatal do Rio de Janeiro, 20I3. 
que sustenta las argumentaciones que aquí se exponen. Asimismo, se incluyen nuevos datos procedentes de mis trabajos en curso acerca de los procesos de victimización y de los movimientos transnacionales de las migrantes rumanas.

III. Redes informales y cultura migratoria

El estudio de las redes para la migración cuenta con una larga tradición en ciencias sociales. En cierta forma, redes y migración son fenómenos conexos, aunque de lo que aquí se trata es de deslindar las redes organizadas de aquellas otras constituidas por grupos fraternales o solidarios, lo que convenimos en denominar como redes de apoyo o redes informales. Así por ejemplo, Dolores Juliano afirma que el recurrir a redes de apoyo ha sido siempre una estrategia común en cualquier proyecto migratorio y cita asimismo los estudios de autores que subrayan la importancia de todas estas organizaciones informales como vehículos de información para las migrantes ${ }^{20}$. Por su parte, GiménEZ ROMERO define las redes migratorias como un conjunto de personas y relaciones que se ocupan de facilitar apoyos al proyecto migratorio ${ }^{2 \mathrm{I}}$, ayuda en la que participan los propios familiares y los amigos de origen, del mismo país, región e incluso del mismo barrio o comunidad ya establecidos en el lugar de destino.

La cuestión que aquí nos interesa es que en relación con el mercado del sexo el debate político y académico tiende a problematizarse, y las redes sociales de apoyo a la migración son tradicionalmente objeto de sospecha y criminalizadas, por lo cual el significado de la idea de transnacionalidad se reconduce, la mayoría de las veces erróneamente, hacia el crimen organizado ${ }^{22}$. Sin embargo, los resultados obtenidos en diferentes estudios empíricos sobre trabajadoras sexuales migrantes avalan la importancia que adquieren las redes informales de apoyo a lo largo de todo el proceso del proyecto migratorio de estas personas. Así, por ejemplo, los estudios realizados por Oso y ULLOA con migrantes colombianas y ecuatorianas; SOLANA sobre trabajadoras sexuales migrantes en Andalucía; Agustín sobre las dinámicas de la industria del sexo mundial; NYBERG con migrantes dominicanas; AZIZE sobre las migrantes de la región del Caribe; TEIXEIRA con travestis brasileñas en Italia; PELÚCIO sobre la migración de travestis a España; RIOPEDRE con migrantes brasileñas y colombianas; HURTADO con migrantes afro-colombianas; PISANI acerca de la industria del sexo en Asia; VARTABEDIAN sobre migraciones de travestis brasileñas; PISCITELLI sobre tránsitos de brasileñas en Italia y España, entre otros. ${ }^{23}$ En

${ }^{20}$ Juliano, Dolores, «El peso de la discriminación: debates teóricos y fundamentaciones» en Osborne (ed.), Trabajador@s del sexo. Derechos, migraciones y tráfico en el siglo XXI, Barcelona, Bellaterra, 2004, págs. 43-55

2I GIMÉnEZ, Carlos, Qué es la inmigración, Barcelona, RBA, 2003

22 Piscitelli, Adriana, Trânsitos: brasileiras nos mercados transnacionais do sexo, Rio de Janeiro, Universidade Estatal do Rio de Janeiro, 2013

23 Oso, Laura y UlLOA, Marcela, «Tráfico e inmigración femenina desde la voz de las mujeres inmigrantes», Tráfico e inmigración de mujeres en España. Colombianas y ecuatorianas en los servicios domésticos y sexuales, Madrid, ACSUR Las Segovias, 200I, págs. 65-II8; SolAnA, José Luis, Prostitución, tráfico e inmigración de mujeres, Granada, Comares, 2003; NYBERG, Ninna, «Migración, género y desarrollo: el caso dominicano» en Zúñiga (cord.), La migración, un camino entre el desarrollo y la cooperación, Madrid, Centro de Investigaciones para la Paz, 2005, págs. I63-I82; AzIZE, Yamila, «Empujar las fronteras: mujeres y migración internacional 
todos ellos se evidencia una preponderancia de la acción de las redes informales en los distintos procesos migratorios, destacando la intervención de familiares, amigos y conocidos en varias de las fases de esos procesos. No hay apenas conexiones con grupos organizados o mafiosos, sino que se trata de migraciones de tipo autónomo donde las redes establecen relaciones de solidaridad, proporcionando información, recursos, bienes, contactos, etc., haciendo viable el proyecto migratorio ${ }^{24}$. En muchos casos la ayuda prestada por estas redes informales es sin ánimo de lucro, aunque también hay situaciones en las que entre parientes se pactan préstamos con interés variable, por lo general más bajo que en el mercado.

«Mi hermana ya empezó a llamarme y a decirme que viniese para España, que ella me iba a meter los papeles. Mi papá también se mostraba interesado en que viajase» (Ángela) ${ }^{25}$

«Yo llevaba mucho tiempo escuchando hablar de España a las compañeras. Unas hablaban de España, otras de Italia,... Entonces, un día una amiga me dijo que conocía a una mujer que le ayudaba para viajar a España. Yo le dije que, por favor, me la presentase» (Bárbara) ${ }^{26}$

Los motivos para viajar no son siempre los mismos. Junto a la presión de las circunstancias socio-económicas se evidencian también deseos subjetivos. Esta realidad aparece constantemente en las distintas trayectorias y narraciones de las migrantes, por lo que pretender reducir sus proyectos migratorios a las típicas constricciones estructurales equivale a deshumanizar a estas mismas migrantes. Como afirma AGUSTín: «Ser económicamente pobre no te hace pobre espiritualmente ${ }^{27}$. De hecho, incluso en aquellas migraciones que categorizamos como económicas, no deja de existir una poli-motivación que engloba sueños, ansias de aventura, deseos de cambiar de rumbo en la vida, etc.

«Cuando mi hija cumplió cinco años fue cuando yo empecé a pensar en la posibilidad de viajar a España. Yo conocía a una señora que había viajado a España y

desde América Latina y el Caribe» en Osborne (ed.), Trabajador@s del sexo. Derechos, migraciones y tráfico en el siglo XXI, Barcelona, Bellaterra, 2004; PeLúcio, Larissa, «Sin papeles, pero con glamur. Migración de travestis brasileñas a España», Vibrant, v.6, nffl I, 2009, págs. I70-I97; RIOPEDRE, José, Inmigración colombiana y brasileña y prostitución femenina en la ciudad de Lugo: Historias de vida de mujeres que ejercen la prostitución en pisos de contactos, Tesis doctoral, departamento de Sociología I, Facultad de Ciencias Políticas y Sociología, UNED, 2oio; HuRTAdo, Teodora, Mujeres, Negras e Inmigrantes construyendo la ocupación de «proveedoras» de servicios afectivos y «vendedoras» de bienes erótico-amorosos en los espacios transnacionales, Tesis doctoral, México, Universidad Autónoma Metropolitana, División de Ciencias Sociales y Humanidades, 20II; PISANI, Elizabeth, La sabiduría de las putas. Burócratas, burdeles y el negocio del sida, Madrid, Sexto Piso, 20I2; VARTABEDian, Julieta, Geografía Travesti: cuerpos, sexualidad y migraciones de travestis brasileñas (Rio de Janeiro-Barcelona), Tesis doctoral, Facultad de Geografía e Historia, Universidad de Barcelona, 20I2; PISCITELLI, Adriana, Trânsitos: brasileiras nos mercados transnacionais do sexo, Rio de Janeiro, Universidade Estatal do Rio de Janeiro, 20I3.

24 Mestre, Ruth, «Género y extranjería» en Briz y Garaizábal (coords.), La prostitución a debate. Por los derechos de las prostitutas, Madrid, Talasa, 2007, págs. 65-70

25 Entrevista, 29 de abril 2006.

${ }_{26}^{6}$ Entrevista, 9 de noviembre de 2004.

27 Agustín, Laura, Trabajar en la industria del sexo y otros tópicos migratorios, San Sebastián, Gakoa, 2004 
que luego volvió a Rondônia sólo para vender sus propiedades. Me contó que en España la vida era mejor, aunque era difícil encontrar trabajo. Yo le dije que estaba decidida a trabajar en cualquier cosa. Y mi matrimonio ya no tenía ningún sentido.» (Luana) $)^{28}$

«Entonces, cuando tenía veintiún años, comenzó a surgir en mi cabeza la idea de salir de Brasil y de viajar a Europa. Yo quería huir de todo aquello. Dejar atrás toda mi vida anterior.» (Marcela) $)^{29}$

«Esa idea de viajar la tuve siempre, ya desde cuando yo era una adolescente (...) Decidí finalmente venir a España en marzo de 2005. Ahí decidí que venía para acá con el objetivo de cambiar mi vida. Pensaba que las cosas serían más fáciles. Tenía en mente venir, trabajar, ganar dinero para pagar el billete y tal vez poder establecerme en España.» (Estefany) $)^{30}$

«A finales de febrero nos marchamos de Cádiz y viajamos en autobús hasta Lugo. Viajamos toda la noche. Me gusta viajar. Hasta que cumplí los diecinueve años yo no conocía nada. Fue cuando llegué a Europa que cambié mucho, y ahora me gusta conocer gente y cosas diferentes. Es mismo la aventura. Mi familia también fue percibiendo ese cambio. Para mí el venir a Europa me ha abierto muchas oportunidades y muchos caminos.» (Vivian) $)^{3 \mathrm{I}}$

Durante mi investigación con migrantes brasileñas y colombianas (2010) la mitad de la muestra se correspondía con un modelo de migración autónoma y/o con apoyo de redes informales. En el resto de casos eran las propias migrantes quienes acudían voluntariamente a redes organizadas ${ }^{32}$ y establecían diferentes tipos de acuerdos con el fin de poder viajar y/o establecerse para trabajar en España. Incluso en estos últimos casos, las redes de apoyo se mostraron más tarde determinantes tanto para cambiar de lugar de trabajo como para cruzar nuevas fronteras. Así lo estamos observando ahora también con las trabajadoras sexuales migrantes con permiso de residencia español y que se están marchando a países como Francia, Suiza, Reino Unido o Alemania a hacer sus plazas o a establecerse allí de forma indefinida, donde los contactos de amigas y las cadenas migratorias preestablecidas no son sólo necesarios, sino que condicionan el éxito o fracaso de la aventura migratoria.

«Desde el momento en que me marché de Lugo me instalé en Toulon. Allí me quedé un mes. Después me fui a Cannes y allí estuve trabajando con cuatro amigas, tres brasileñas y una argentina. Pero, no estuve todo el tiempo trabajando, sino que

${ }^{28}$ Entrevista, I4 de julio 2005.

29 Entrevista, 24 de marzo 2005.

30 Entrevista, 28 de octubre 2005 .

3I Entrevista, 2I de marzo 2005.

32 Se trata más bien de redes de contactos y reclutadores que funcionan como intermediarios entre las migrantes y algunos negocios del mercado del sexo en el lugar de destino, y no tanto de organizaciones o tramas del crimen transnacional. 
aproveché también para pasear, ir a la playa y conocer gente... Cannes tiene unas playas maravillosas. De Cannes me fui luego para Annecy, que es una población ya cerca de la frontera con Suiza, y allí me quedé un mes. Más tarde me trasladé a Dijon porque, ya sabes, cuando el trabajo baja tienes que marcharte y buscar lugares mejores para trabajar, sino te estancas. En Dijon estuve trabajando durante un mes y después tomé la decisión de tomarme unas pequeñas vacaciones en Suiza. Quería conocer Ginebra y me fui de viaje con tres amigas. Ginebra es una ciudad muy bonita, tiene un montón de parques y espacios públicos hermosos para pasear y quitar fotos.» (Silvia) ${ }^{33}$

En síntesis, el hecho de recurrir a redes informales de apoyo y a contactos de amigas y conocidas con experiencia previa en los lugares de destino constituye una práctica muy habitual entre las migrantes que se ocupan en la industria del sexo transnacional. Por otro lado, esta misma experiencia puede ser la expresión de un conjunto de prácticas de los sujetos migrantes en lo que podríamos categorizar como una verdadera cultura migratoria. De hecho, muchas de las migrantes que llegaron a España durante la última década traían consigo el peso de una fuerte tradición migratoria, bien sea en el sentido de migraciones internas de zonas rurales del interior a los principales núcleos urbanos o incluso de anteriores migraciones internacionales antes de recalar en nuestro país. Esta tradición migratoria puede verse también reforzada a través de la movilidad intrínseca al mercado del sexo global, con lo cual las migrantes tienden a cruzar las fronteras y a vivir en un clima cosmopolita ${ }^{34}$. En el estudio realizado con migrantes colombianas y brasileñas ${ }^{35}$ un tercio de la muestra ya se habían ocupado en el mercado del sexo en sus países de origen. Los estudios de HURTAdo y PISCITELL ${ }^{36}$ corroboran estos mismos resultados. Así, algunas de estas mujeres se desplazaron antes de viajar a Europa a países como Argentina, Venezuela o Guayana, mientras otras viajaron directamente a Europa pero antes de llegar a España permanecieron durante un tiempo trabajando en Portugal o Suiza. En cualquiera de estos desplazamientos las migrantes recurren al auxilio de sus redes informales.

«Mi novio me agobiaba demasiado. Él era muy celoso y entonces decidí, con dieciocho años, marcharme con una amiga para la Guayana francesa. Estuvimos en Kourou durante unos cinco meses. Ahí fue que empecé a prostituirme, y también cuando experimenté con drogas duras como el crack.» (Flávia) ${ }^{37}$

\footnotetext{
33 Entrevista, 27 de setiembre 2012.

34 Agustín, Laura, Trabajar en la industria del sexo y otros tópicos migratorios, San Sebastián, Gakoa, 2004

35 Riopedre, José, Inmigración colombiana y brasileña y prostitución femenina en la ciudad de Lugo: Historias de vida de mujeres que ejercen la prostitución en pisos de contactos, Tesis doctoral, departamento de Sociología I, Facultad de Ciencias Políticas y Sociología, UNED, 2010

${ }^{6} 6$ HurTAdo, Teodora, Mujeres, Negras e Inmigrantes construyendo la ocupación de «proveedoras» de servicios afectivos y «vendedoras» de bienes erótico-amorosos en los espacios transnacionales, Tesis doctoral, México, Universidad Autónoma Metropolitana, División de Ciencias Sociales y Humanidades, 20Ir; PisciTELLI, Adriana, Trânsitos: brasileiras nos mercados transnacionais do sexo, Rio de Janeiro, Universidade Estatal do Rio de Janeiro, 2013

37 Entrevista, 27 de enero 2006.
} 
«Luego conocí a una chica en mi país y me aconsejó que me metiera en la prostitución. Ahí estuve durante ocho años trabajando en la prostitución en Colombia. Me marché para Bogotá. El dinero alcanzaba sólo para sobrevivir. Y entonces decidí viajar a España.» (Natalia) $)^{38}$

«En la Langestrasse trabajé muy bien, tanto que pude alquilar un apartamento de mil seiscientos francos. Un apartamento para mí sola. En aquella época en la Langestrasse todas las prostitutas nos colocábamos en diferentes puntos en la calle.» (Vivian) $)^{39}$

«Existen casos de engaño en la prostitución. Pero, la mayoría de las mujeres que vienen a prostituirse a España ya se prostituían en Brasil. Para ellas viajar a Europa es como dar el salto a la universidad. Una prostituta en Brasil ya gana mucho dinero. Pero, las que vienen aquí a España, a Italia, a Portugal vienen para ganar el triple. Algunas tienen casas y negocios en Brasil y vienen aquí para sufragar los gastos y pagar las deudas.» $(\mathrm{Bia})^{40}$

Desplazamientos similares se observan asimismo en las migrantes del Este de Europa. Tradicionalmente los movimientos migratorios de este colectivo sufren la estigmatización de mostrarse públicamente a través de los medios y de las instituciones siempre condicionados al crimen organizado, sin embargo, las entrevistas realizadas con trabajadoras sexuales rumanas y ucranianas contradicen este estereotipo. En los años noventa fueron muchas las mujeres rumanas que viajaron a Turquía y que trabajaron en la prostitución durante períodos de tres meses. En la década siguiente Grecia, Italia y España fueron los principales destinos, mientras hoy con el advenimiento de la crisis económica en el sur de Europa otros países como Francia, Suiza o Reino Unido han ocupado este lugar, consolidando así la ampliación del espacio transnacional para el ejercicio de la prostitución $^{4 \mathrm{I}}$.

«Antes de venir a España trabajé también en Turquía con mi hermana y una amiga. Allí no es como aquí, el trabajo es más en hoteles y tienes que vestir bien. Muchas amigas rumanas también viajan a Italia, allí se trabaja en la calle y se puede ganar mucho dinero.» (Elena) $)^{42}$

$3^{8}$ Entrevista, I de febrero 2003.

39 Entrevista, I8 de marzo 2005.

$4 \circ$ Entrevista, I9 de agosto 2005.

$4^{\mathrm{I}}$ Véase en este sentido el relato biográfico de una migrante rumana en SolANA y RIOPEDRE, Trabajando en la prostitución. Doce relatos de vida, Granada, Comares, 20I2..

42 Entrevista 2 de marzo 2013. 
«Yo ya había trabajado antes en la prostitución. Antes de decidirme a venir a España trabajé en Hungría y también en Alemania, siempre en clubes.» (Alexandra) ${ }^{43}$

Al igual que en el caso de las migrantes del este europeo, existen otros colectivos ampliamente victimizados como las trabajadoras sexuales nigerianas y marroquíes que viajan a Europa y que en muchos casos no recurren a redes organizadas, sino que lo hacen de forma autónoma o bien se sirven de redes familiares de apoyo. Así, he podido encontrar en Galicia a mujeres de Casablanca y de Benin City que se corresponden con este modelo de migrantes transnacionales.

«Yo llegué a España desde Francia, por París, y viajé en avión. La mayoría de mi gente viaja en avión, un vuelo desde Madrid a Benin City son solo cuatro horas; mi hermano ya ha viajado en 'ida y vuelta' el mismo día. Luego en la policía cuando me preguntaron también respondí que llegué a España en barco, pero no es verdad. Y las mafias no andan detrás de la gente, somos las mismas personas las que acudimos a ellas para solicitar ayuda para viajar. Y ellos entonces ponen unas condiciones que tienes que cumplir. Lo demás es todo mentira.» (Erika) ${ }^{44}$

Erika se mueve por toda España trabajando en la prostitución y recientemente ha dado el salto a Francia y al Reino Unido. A la vez mantiene contactos y gestiona algunos negocios en Nigeria. El estudio de KASTNER ${ }^{45}$ acerca de las migrantes nigerianas establecidas en Andalucía menciona también la existencia de un flujo de migración autónoma para este colectivo ${ }^{46}$. Todas estas migraciones transnacionales guardan también relación con la propia cronología de las diferentes corrientes migratorias, siendo entonces que a mayor tiempo de permanencia en el lugar de destino, mayores posibilidades de consolidar redes de apoyo. Esto lo hemos visto, por ejemplo y para el caso de Galicia, con la sucesión de los flujos migratorios de dominicanas, colombianas, brasileñas y rumanas a lo largo de las últimas tres décadas, relevo migratorio que ha modificado también paulatinamente el panorama étnico en la industria del sexo regional47. Así, una de las últimas corrientes migratorias en la comunidad gallega ha sido la de migrantes paraguayas, situación que explica en parte la dependencia todavía de este colectivo de redes organizadas para la migración. Por el contrario, el caso de la más reciente oleada de migración dominicana cuenta con importantes antecedentes en su implantación en España, con lo que las redes informales facilitan mejor su inserción en destino. Y sucede algo similar en el caso

\footnotetext{
43 Entrevista 2004. Véase relato biográfico en Riopedre, Mara y sus amigas, Lugo, Manuscritos, 2004.

44 Entrevista, 26 agosto 2015.

45 KASTNER, Kristin, «Cuerpo, corporeidad y migración. Nigerianas a ambos lados del Estrecho» en Solana y Acién (eds.), Los retos de la prostitución. Estigmatización, derechos y respeto, Granada, Comares, 2008, págs. 45-57

${ }^{4} 6 \mathrm{Si}$ bien aclara que es minoritario en comparación con las corrientes migratorias que sí recurren a redes organizadas.

47 Riopedre, José, «Situación presente de la prostitución en el contexto gallego (2000/II) » en Iglesias y Puente (coords.), Sistema penal y perspectiva de género: trabajo sexual y trata de personas, Granada, Comares, 2012, págs.I2I-I55
} 
de las marroquíes, donde la fuerte implantación de este colectivo en España favorece también la emergencia de las redes solidarias de apoyo a la migración.

Por último, las circunstancias de creciente criminalización y clandestinidad del mercado del sexo, por su parte, revalorizan aún más la importancia de este tipo de redes, cuya ayuda e información resulta vital para que las trabajadoras sexuales puedan sortear los numerosos obstáculos a que se enfrentan durante el desempeño de su actividad. Esto se observa bien ahora con las transmigrantes brasileñas, colombianas y dominicanas que se desplazan desde España a Francia para trabajar allí en la prostitución.

\section{Criminalización y movilidad}

Podemos hablar de movilidad en el sentido geográfico, aludiendo a la capacidad que tienen las migrantes de desplazarse por el espacio transnacional y cruzar las fronteras, y asimismo en su acepción de movilidad social, queriendo aludir al deseo de las migrantes de ascender de posición en la estructura social. Ambos significados del término movilidad no son excluyentes, sino que se complementan pues, por lo general, las migrantes viajan y cambian de destino y lugar de trabajo en aras de maximizar beneficios y ascender socialmente. Hay que reconocer que en muchos casos no se accede a la prostitución para sobrevivir, sino para alcanzar un mayor nivel adquisitivo y acceder a más bienes de consumo. Paradójicamente, las trabajadoras sexuales se sirven de una ocupación terriblemente estigmatizada con el fin de alcanzar un mejor estatus social.

El modelo abolicionista imperante en España, aunque victimiza a las trabajadoras sexuales migrantes, tiende a criminalizar la prostitución de forma global. Esta victimización de las migrantes forma parte, al mismo tiempo, de un conjunto de prácticas estigmatizadoras supuestamente protectoras o estigmatización benefactora ${ }^{4}{ }^{8}$. En Europa el punto de inflexión lo ha puesto Suecia con la aprobación en I999 de la Ley de prohibición de compraventa de servicios sexuales mediante la cual se tipifica penalmente por primera vez la figura del cliente. Llama bastante la atención que en un país con una población estimada de apenas un millar de trabajadoras sexuales en las calles ${ }^{49}$ se haya optado por abanderar la lucha contra la prostitución a nivel mundial, pero lo cierto es que la presión de las instancias gubernamentales y de algunas organizaciones suecas han obtenido resultados y el modelo abolicionista radical tiende a exportarse a otros países del entorno europeo. España no ha permanecido ajena a esta nueva oleada de neo-conservadurismo moral ${ }^{50}$ y el sistema abolicionista penalizador toma cuerpo en las sucesivas reformas del Código Penal y de la Ley de Extranjería, así como en las ordenanzas municipales de capitales españolas como Barcelona, Bilbao, Sevilla, Málaga, Murcia o Valencia, entre otras muchas, donde se expulsa a las trabajadoras sexuales de los centros urbanos y, bajo el paraguas de un

\footnotetext{
$4^{8}$ Nieto, José A., Sociodiversidad y sexualidad, Madrid, Talasa, 20II

49 Kulick, Don, «Sex in the New Europe: The Criminalization of Clients and Swedish Fear of Penetration», Anthropological Theory, 3 (2), 2003, págs. 199-2I8

50 RiopedRE, José, «La criminalización de la industria del sexo, una apuesta políticamente correcta», Gazeta de Antropología, nffl 27/2, $201 \mathrm{I}$
} 
supuesto mantenimiento de la convivencia ciudadana y la lucha contra la trata y la explotación sexuales, se sanciona a prostitutas y clientes por igual. En el mismo sentido se activan los diferentes Planes integrales de lucha contra la trata de personas y la explotación sexual que derivan invariablemente en la criminalización y estigmatización de los actores sociales, incidiendo muy negativamente en las propias migrantes.

Frente a estos efectos arrolladores del lobby abolicionista que en España y en Europa toman cuerpo en una poderosa industria de la salvación ${ }^{5 I}$ que crece y que propaga su discurso hegemónico a través de la afiliación dionisíaca y del postureo político, el margen de maniobra de la industria del sexo y de las migrantes es bien reducido, expresándose a través de tímidas reivindicaciones desde algunos sectores y movimientos sociales, la constitución de asociaciones y cooperativas de trabajadoras sexuales y en el peor de los casos con la propia claudicación de las migrantes y su asunción del discurso de la victimización.

Como advierte PISCITELLI, el comienzo de la crisis económica coincide además en el tiempo con el advenimiento y auge de todas estas ordenanzas municipales que persiguen a trabajadoras sexuales y clientes que negocian en la calle, imponiendo duras sanciones económicas a quienes infringen la normativa ${ }^{52}$. La detención policial y las órdenes de expulsión son otra consecuencia directa de la criminalización de la prostitución. No obstante, y a pesar del endurecimiento de la legislación de extranjería, en los últimos años se observa una progresiva regularización de las trabajadoras sexuales migrantes, sobre todo de algunos colectivos como las procedentes de Latinoamérica, quienes cuentan con una mayor tradición migratoria en España, por lo que en muchos lugares de trabajo la mayoría de las migrantes tienen ya sus permisos de residencia en regla e incluso poseen la nacionalidad española. Algo parecido sucede con las migrantes rumanas o de otros países pertenecientes a la Unión Europea, a quienes les salvaguarda, en principio, su condición de ciudadanas comunitarias. En el resto de los casos las migrantes son extremadamente vulnerables a la discreción policial53 y se ven sometidas, muchas veces en contra de su voluntad, a una movilidad forzosa y/o al ejercicio de su actividad en condiciones más precarias. Esto sucede también cuando se precintan locales en el marco de grandes operaciones judiciales contra la prostitución y la explotación sexual, fenómeno que resulta casi más determinante en la movilidad forzosa de las trabajadoras sexuales que la posible acción de proxenetas y traficantes.

5I Expresión acuñada por Agustín (Trabajar en la industria del sexo y otros tópicos migratorios, San Sebastián, Gakoa, 2004; y Sexo y marginalidad. Emigración, mercado de trabajo e industria del rescate, Madrid, Editorial Popular, 2009) con la que apunta a todo el entramado de burócratas y organizaciones no gubernamentales que han terminado haciendo un verdadero negocio de la salvación y protección de las víctimas, con lo que promueven ampliamente la victimización. Véase también en este sentido el trabajo de PisAni (La sabiduría de las putas. Burócratas, burdeles y el negocio del sida, Madrid, Sexto Piso, 20I2).

52 Piscitelli, Adriana, Trânsitos: brasileiras nos mercados transnacionais do sexo, Rio de Janeiro, Universidade Estatal do Rio de Janeiro, 2013

53 Riopedre, José, Inmigración colombiana y brasileña y prostitución femenina en la ciudad de Lugo: Historias de vida de mujeres que ejercen la prostitución en pisos de contactos, Tesis doctoral, departamento de Sociología I, Facultad de Ciencias Políticas y Sociología, UNED, 2о о 


\section{Efectos de la crisis económica en la prostitución}

Todas las trabajadoras sexuales entrevistadas informan de una considerable disminución de los beneficios en el mercado del sexo nacional a causa de la crisis. Según algunos de los estudios sobre la cuestión podemos hablar de una reducción de alrededor del $60 \%$ en $20 \mathrm{II}^{54}$. Y no nos referimos solamente a una significativa disminución de la demanda, sino también a una reducción en los precios. Así, el coste de un servicio básico se mantiene en parámetros similares a hace más de una década y oscila entre los i5 euros que en los peores casos se negocian en la calle con los 50/60 euros de la mayoría de los clubes. Estas circunstancias, obviamente, no sólo están influyendo, sino que están modificando las propias dinámicas en la industria del sexo.

Tal y como ha sucedido en otros espacios de nuestra economía, en los mercados del sexo el sector de más alto standing es el que ha sabido mejor sortear la crisis. Esto explica que actualmente uno de los negocios más rentables de esta industria sean también las saunas y locales tántricos donde el trabajo sexual se difumina y presuntamente se desexualiza bajo el aparato de un glamuroso manto de parafernalia pseudo-espiritual.

Por otro lado, si bien las actuales políticas criminalizadoras de la prostitución tienen su influencia en la movilidad de las trabajadoras sexuales, se observa que la acción de la crisis económica está siendo mucho más determinante en las dinámicas de la industria del sexo. Esto es así porque las migrantes anteponen las posibilidades de obtener un mayor beneficio económico a los inconvenientes derivados de la propia persecución de la prostitución. Sólo así se explica que muchas de las migrantes brasileñas que cuentan con arraigo y permiso de residencia en España se marchen ahora a trabajar a países como Francia, Suiza, Bélgica, Reino Unido o Dinamarca con legislaciones incluso más restrictivas que en España. La razón, como ellas explican, es que vale la pena arriesgarse porque «se gana mucho más dinero que en España». Otros lugares de destino son Holanda o Alemania, los cuales a pesar de tener una normativa despenalizadora de la prostitución que reglamenta el sector, no están exentos de problemas debido a que sus actuales modelos bloquean la regularización directa de las migrantes en el mercado del sexo nacional. Dominicanas y colombianas siguen a las brasileñas en estas rutas del trabajo sexual transnacional. Se observa incluso el caso de mujeres que trabajaban desde hace años en la misma localidad y que, de repente, deciden cruzar nuevamente las fronteras movidas por la crisis.

«El sistema de trabajo en Francia es diferente al de España. En Francia tienes que tener más cuidado, la prostitución está muy perseguida, no es como aquí. Nosotras colocamos los anuncios sólo por internet. Si te anuncias en una ciudad pagas I20 euros, si te desplazas a otro sitio son 220 euros. Y luego cada semana tienes que

54 Piscitelli, Adriana, Trânsitos: brasileiras nos mercados transnacionais do sexo, Rio de Janeiro, Universidade Estatal do Rio de Janeiro, 20I3 
pagar una cuota de sesenta euros para que mantengan tu anuncio en las primeras posiciones.» (Silvia) $)^{55}$

«Estando en un club en Santiago fue cuando conocí a Daniela, una brasilera que es fisioterapeuta y que trabajaba allí porque quería ahorrar para montar una clínica de fisioterapia. Daniela era una chica tímida, pero nos hicimos amigas. Fue ella quien me contó que había estado trabajando en Dinamarca, en una casa de citas. Me dijo que había ganado 8.000 euros en dieciséis días. Me contó que la dueña te entregaba una hoja con unas palabras en inglés y la traducción en portugués. Entonces, le pedí el contacto (...) El sistema allí era así, al cincuenta por ciento. Y en cada casa sólo trabajaba una chica. En la cabaña había una lucecita como las de Navidad, y esa era la única señal de que aquello era una casa de citas. Victoria hacía todo, nos daba los condones, contactaba con los clientes, etc. Los pases allí eran a partir de 600 coronas (unos 80 euros más o menos).» (Sandra) $)^{56}$

El desempeño del trabajo sexual en Francia y otros países centroeuropeos para las migrantes latinoamericanas que han consolidado su residencia en España tiene otra peculiaridad como es el aprendizaje de otro idioma (francés, alemán, inglés) y en la dinámica interna del negocio esto significa la necesaria contratación de un intermediario/a para establecer el primer contacto con los clientes (atender el teléfono, escribir un email), lo cual resta asimismo una parte de los beneficios, al menos durante el tiempo en que las trabajadoras sexuales no logran desenvolverse bien en el nuevo idioma. Así por ejemplo, en Francia las migrantes brasileñas subcontratan estos servicios con otras migrantes más expertas o con nacionales, a las que ellas llaman traductoras, muchas veces francesas de origen africano.

La osadía de las migrantes llega hoy en algunos casos al extremo de aventurarse en países tan lejanos geográfica y culturalmente como Dubai o Qatar, donde existe la posibilidad de obtener cuantiosos beneficios, o en Suecia, paradójicamente la quintaesencia del abolicionismo mundial donde desde instancias gubernamentales se jactan de haber «casi» exterminado la prostitución.

«Llevo varios meses trabajando en Inglaterra, cerca de Londres, allí trabajo como 'call-girl', no de noche, sino durante el día. Allí se gana bien, un servicio mínimo se paga con 70 pounds (unos cien euros aproximadamente), y está muy bien. Como tengo la doble nacionalidad (española/ brasileña) no tengo problema. Y ya hablo un poco de inglés. Así, mientras estuve en Lugo también aproveché para estudiar y fui durante un año y medio a la escuela de idiomas [...] Desde Inglaterra también me muevo a otros lugares, he ido por ejemplo a Estocolmo en Suecia. Allí hay movimiento a pesar de la ley que tienen, y hay muchas mujeres que van a trabajar

\footnotetext{
55 Entrevista, 25 de setiembre 2012.
}

${ }^{56}$ Entrevista, 28 de enero de 2012. 
allí, pero está mejor en Copenague (Dinamarca) porque la corona danesa tiene más valor.» (Cristina) $)^{57}$

En otros casos, la crisis económica que afecta al sector está cambiando sensiblemente las expectativas de las migrantes y puede motivar incluso el abandono temporal o definitivo de la prostitución. Así, algunas migrantes brasileñas han optado también por regresar a su país, en este caso una economía emergente que ofrece nuevas oportunidades de trabajo y que está atrayendo ahora a migrantes europeos.

«Ya estoy un poco cansada de trabajar en la prostitución. Aquí en España la cosa ahora está muy mal. Una amiga mía dice que 'antes teníamos dinero, pero no teníamos papeles; y ahora tenemos papeles pero no tenemos dinero', y tiene razón (...) Antes de viajar a Brasil hice unas plazas en Italia, también en Suiza en la parte italiana. Pero, ahora ya no quiero más, ya no vale tanto la pena como antes, y pienso en regresar a mi país, o tal vez marcharme para Inglaterra, donde tengo a mi hermana.» (María) $)^{8}$

Al igual que María, otras migrantes piensan en regresar a Brasil o bien se han marchado ya, algunas acompañadas de sus parejas españolas y con la idea conjunta de comenzar un nuevo ciclo de vida al otro lado del Atlántico. Los efectos de la crisis resaltan más aún debido al contraste observado en el conjunto de los movimientos migratorios en España en un período de tiempo tan corto como son apenas dos décadas. Así, si tenemos en cuenta datos estadísticos del crecimiento del fenómeno migratorio en España a partir de los años noventa ${ }^{59}$ coincidente con la expansión de los mercados del sexo en nuestro país, observaremos que este repunte de ambos fenómenos tropieza luego bruscamente con el inicio de la crisis económica a finales de la última década, consolidándose un período caracterizado por el desempleo, la precariedad laboral, la subida de impuestos, el retorno de muchos inmigrantes a sus países de origen y la nueva ola de emigración de españoles. Ante tal panorama macro-económico, sería imposible que la industria del sexo nacional no se viese seriamente afectada.

Sin embargo, mientras se produce el retorno y la salida de España de migrantes brasileñas, son las migrantes de otras nacionalidades las que continúan nutriendo la industria del sexo nacional. Casos paradigmáticos son la nueva oleada de migrantes dominicanas hacia España así como el constante flujo de migrantes rumanas. En ambos casos, el auxilio de las redes informales y familiares condiciona el éxito del proyecto migratorio, al igual que la problemática de la crisis en el sur de Europa queda eclipsada por los graves problemas estructurales que asolan a estos países: desempleo, incremento de la delincuencia, protección social deficitaria, corrupción, etc.

\footnotetext{
57 Entrevista, 24 de abril 2015.

$5^{8}$ Entrevista, I7 de abril de 2013.

59 Véase por ejemplo HuRTAdo, Mujeres, Negras e Inmigrantes construyendo la ocupación de «proveedoras» de servicios afectivos y «vendedoras» de bienes erótico-amorosos en los espacios transnacionales, Tesis doctoral, México, Universidad Autónoma Metropolitana, División de Ciencias Sociales y Humanidades, 2OII
} 
El debilitamiento de las redes sociales de apoyo a las migrantes en España a causa de la crisis producirá seguramente efectos negativos en el establecimiento e integración de esas migrantes en el futuro. Por otro lado, la consolidación del modelo abolicionistaprohibicionista en nuestro país a través de las sucesivas reformas penales y de la normativa de extranjería, junto a la proliferación de ordenanzas municipales criminalizadoras de la prostitución, están construyendo un contexto de paroxismo punitivo claramente hostil hacia las trabajadoras sexuales, precarizando las condiciones laborales, haciendo más vulnerables a las personas y sometiéndolas a un paulatino y creciente intervencionismo estatal de más largo alcance que el propio fenómeno migratorio. En este contexto, resulta difícil pensar en una posible normalización del sector y en un deseable empoderamiento de las trabajadoras sexuales, lo que significa también que se crea el clima idóneo para que proliferen los abusos y las actividades del crimen organizado. Y en este estado de cosas, la torticera y demagógica confusión entre fenómenos sociales tan diferentes como trabajo sexual, trata de personas, explotación sexual, tráfico y violencia de género, auspiciada desde los poderes públicos y organizaciones de la industria del rescate, resulta éticamente intolerable.

Muchas de las migrantes que hoy están ejerciendo el trabajo sexual en otros países europeos posiblemente tenderán a regularizar su situación jurídica en esos países si la crisis en España se cronifica y alarga en el tiempo, modificando posiblemente entonces sus permisos de residencia. La segmentación étnica lógicamente está modificándose y los colectivos de migrantes cuyos países de origen están sufriendo una crisis estructural igual o peor que en España tienden a sustituir a aquellos otros oriundos de regiones en fase de recuperación. Lo estamos viendo, por ejemplo, con las migrantes rumanas, quienes tienden a sustituir a brasileñas y colombianas en muchos negocios del mercado del sexo. Algunos estudiosos de las migraciones hablan en los últimos años del fenómeno de la creciente rumanización de la migración en España ${ }^{60}$, lo que se evidencia muy bien en el ámbito del trabajo sexual. En relación con esto último llama poderosamente la atención el hecho de que existan aún pocos estudios empíricos sobre la migración rumana en nuestro país, máxime teniendo en cuenta que ya constituyen el primer país de procedencia de nuestros inmigrantes, con cerca de novecientos mil migrantes censados ${ }^{6 \mathrm{I}}$. En cuanto a las trabajadoras sexuales de esta nacionalidad la ausencia de estudios específicos es total, lo que contrasta también con su presencia muy significativa en el mercado del sexo nacional.

Por otro lado, y en el marco de una nueva configuración de la economía mundial, cabe permanecer atentos a la posible reversión de algunos flujos migratorios, donde algunos países como Brasil o Colombia hasta hace poco fuertes emisores de migrantes hacia Europa, pueden, en cambio, actuar ahora en su calidad de economías emergentes como importantes focos de atracción de migrantes de los países del Norte. Con el mercado del sexo esta nueva configuración mundial cobra pleno sentido por ejemplo en el caso de

60 ViRUELA, Rafael, «Inmigrantes rumanos en España: aspectos territoriales y procesos de sustitución laboral», Scripta Nova, vol. X, nffl 222, I de octubre de 2006.

6r Datos del INE, 2012. 
Brasil con la celebración del Campeonato Mundial de Fútbol en 20I4 y la más reciente de los Juegos Olímpicos en 20i6, especulándose desde hace tiempo con la llegada masiva de trabajadoras sexuales a este país ${ }^{62}$ lo que había generado un vivo debate también en las instituciones gubernamentales.

Por último, y de acuerdo con las reivindicaciones realizadas por otros investigadores sociales $^{63}$ sería muy deseable y fértil superar el paradigma de la victimización y poder incluir, sin complejos, a las trabajadoras sexuales migrantes en los estudios académicos sobre migración y el espacio transnacional, reconociendo así su papel de actores sociales y todo el potencial subjetivo de transformación social que poseen las migrantes de cualquier condición. Para dar este paso necesario deberemos de comenzar por abandonar prejuicios ideológicos y morales, y distanciarnos del etnocentrismo post-moderno. Un segundo reto pasa por hacer un esfuerzo que incluya redes de colaboración académica en el marco de las migraciones internacionales, complementando los estudios locales con los que ya contamos con nuevos estudios con un enfoque más amplio ${ }^{64}$. Sólo así avanzaremos en una comprensión más global de los continuos y rápidos cambios y transformaciones sociales que caracterizan a los procesos migratorios.

VII. Bibliografía

Agustín, Laura, Trabajar en la industria del sexo y otros tópicos migratorios, San Sebastián, Gakoa, 2004

Agustín, Laura, Sexo y marginalidad. Emigración, mercado de trabajo e industria del rescate, Madrid, Editorial Popular, 2009

AlCALDE, Rosalina, «Cosas de mujeres: familias monoparentales dominicanas en Barcelona y Nueva York», Revista Internacional de Organizaciones, n 6, 20II, págs. I09-I34

AzIZE, Yamila, «Empujar las fronteras: mujeres y migración internacional desde América Latina y el Caribe» en Osborne (ed.), Trabajador@s del sexo. Derechos, migraciones y tráfico en el siglo $X X I$, Barcelona, Bellaterra, 2004

BETRISEY, Débora, «Migración y trata de personas para la explotación laboral en talleres textiles de la ciudad de Buenos Aires-Argentina- Génesis social y política bajo el proyecto económico neoliberal», Latin American Perspective, 2014

Cohen, Stanley, Folk Devils and Moral Panics, London and New York, Routledge, 20II/ v.o. 1972

FoucAult, Michel, Historia de la sexualidad. I. La voluntad de saber, Madrid, Siglo XXI, 2005/v.o. 1976

GiMÉNEZ, Carlos, Qué es la inmigración, Barcelona, RBA, 2003

Glick SCHILler, Nina; BASCH, Linda y SzANTON, Cristina, «De inmigrante a transmigrante: aproximación teórica de la migración transnacional» en Sánchez (ed.), La Etnografía y sus aplicaciones. Lecturas desde la Antropología social y cultural, Madrid, Ramón Areces, 2009, págs. 325-354

62 Piscitelli, Adriana, Trânsitos: brasileiras nos mercados transnacionais do sexo, Rio de Janeiro, Universidade Estatal do Rio de Janeiro, 2013

63 Agustín, Laura, Trabajar en la industria del sexo y otros tópicos migratorios, San Sebastián, Gakoa, 2004; Piscitelli, Adriana, Trânsitos: brasileiras nos mercados transnacionais do sexo, Rio de Janeiro, Universidade Estatal do Rio de Janeiro, 2013

64 Agradezco a Adriana Piscitelli el interesante diálogo mantenido acerca de esta cuestión en noviembre de 2012. 
Hurtado, Teodora, Mujeres, Negras e Inmigrantes construyendo la ocupación de «proveedoras» de servicios afectivos y «vendedoras» de bienes erótico-amorosos en los espacios transnacionales, Tesis doctoral, México, Universidad Autónoma Metropolitana, División de Ciencias Sociales y Humanidades, 2OII

JULIANO, Dolores, «El peso de la discriminación: debates teóricos y fundamentaciones» en Osborne (ed.), Trabajador@s del sexo. Derechos, migraciones y tráfico en el siglo XXI, Barcelona, Bellaterra, 2004, págs. 43-55

KASTNER, Kristin, «Cuerpo, corporeidad y migración. Nigerianas a ambos lados del Estrecho» en Solana y Acién (eds.), Los retos de la prostitución. Estigmatización, derechos y respeto, Granada, Comares, 2008, págs. 45-57

Kulick, Don, «Sex in the New Europe: The Criminalization of Clients and Swedish Fear of Penetration», Anthropological Theory, 3 (2), 2003, págs. 199-2I8

MARCUS, George, «Ethnography in/of the World System: the Emergence of Multi-sited Ethnography», Annual Review of Anthropology, n. 24, I995, págs. 95-II7

Mestre, Ruth, «Género y extranjería» en Briz y Garaizábal (coords.), La prostitución a debate. Por los derechos de las prostitutas, Madrid, Talasa, 2007, págs. 65-70

NiETo, José A., Sociodiversidad y sexualidad, Madrid, Talasa, 20 II

NYBERG, Ninna, «Migración, género y desarrollo: el caso dominicano» en Zúñiga (cord.), La migración, un camino entre el desarrollo y la cooperación, Madrid, Centro de Investigaciones para la Paz, 2005, págs. I63-182

ONG, Aihwa, Flexible Citizenship, the Cultural Logics of Transnationality, Durham, Duke University Press, 1999

Oso, Laura, La migración hacia España de mujeres jefas de hogar, Madrid, Ministerio de Trabajo y Asuntos Sociales, Instituto de la Mujer, I998

Oso, Laura y UlloA, Marcela, «Tráfico e inmigración femenina desde la voz de las mujeres inmigrantes», Tráfico e inmigración de mujeres en España. Colombianas y ecuatorianas en los servicios domésticos y sexuales, Madrid, ACSUR Las Segovias, 200I, págs. 65-II8

Pelúcio, Larissa, «Sin papeles, pero con glamur. Migración de travestis brasileñas a España», Vibrant, v.6, nº I, 2009, págs. I70-197

PISANI, Elizabeth, La sabiduría de las putas. Burócratas, burdeles y el negocio del sida, Madrid, Sexto Piso, 20I2

PisCTITELLI, Adriana, «Brasileiras na indústria transnacional do sexo. Migraçôes, direitos humanos e antropología», Nuevo Mundo Mundos Nuevos, 7, Sección Debates, 2007

Piscitelli, Adriana, Trânsitos: brasileiras nos mercados transnacionais do sexo, Rio de Janeiro, Universidade Estatal do Rio de Janeiro, 2013

PORTES, Alejandro, Globalization from Below: The Rise of Transnational Communities, Princeton University, I997

RAMírEZ, Eugenia, Etnicidad, identidad y migraciones, Madrid, Ramón Areces, 2007

RIBAS, Natalia, «Todo por la familia. La emigración de las familias desde el origen» en Checa y Olmos (eds.), Mujeres en el camino. El fenómeno de la migración femenina en España, Barcelona, Icaria, 2005, págs. I05-II5

RiOPEDRE, José, Mara y sus amigas, Lugo, Manuscritos, 2004

RIOPEDRE, José, Inmigración colombiana y brasileña y prostitución femenina en la ciudad de Lugo: Historias de vida de mujeres que ejercen la prostitución en pisos de contactos, Tesis doctoral, departamento de Sociología I, Facultad de Ciencias Políticas y Sociología, UNED, 20ıo

RIOPEDRE, José, «La criminalización de la industria del sexo, una apuesta políticamente correcta», Gazeta de Antropología, n 27/2, 20II

RIOPEDRE, José, «Situación presente de la prostitución en el contexto gallego (2000/II) » en Iglesias y Puente (coords.), Sistema penal y perspectiva de género: trabajo sexual y trata de personas, Granada, Comares, 20I2, págs.I2I-I55 
RIOPEDRE, José, «La figura del mediador en el mercado del sexo: cafetinas brasileras, traductoras francesas y peste rumano», VIII Congreso sobre Migraciones Internacionales en España, Granada, setiembre 2015.

RiopedRe, José, Mujeres cruzando el Atlántico. Relatos biográficos de migrantes brasileñas en los mercados del sexo, Granada, Comares, 2015

RUBIN, Gayle, «Reflexionando sobre el sexo: notas para una teoría radical de la sexualidad» en Vance (comp.), Placer y peligro. Explorando la sexualidad femenina, Madrid, Talasa, I989, págs. II3190

Solana, José Luis, Prostitución, tráfico e inmigración de mujeres, Granada, Comares, 2003

Solana, José Luis y RiopedRe, José, Trabajando en la prostitución. Doce relatos de vida, Granada, Comares, 2012

TEIXEIRA, Flávia, «L'Italia dei Divieti: entre o sonho de ser européia e o babado da prostituiçâa», Cadernos pagu (3I) 2008, UNICAMP, 2008, págs. 275-308

VANCE, Carole, «El placer y el peligro: hacia una política de la sexualidad» en Vance (comp.), Placer y peligro. Explorando la sexualidad femenina, Madrid, Talasa, I989, págs. 9-49

VARTABEDIAn, Julieta, Geografía Travesti: cuerpos, sexualidad y migraciones de travestis brasileñas (Rio de Janeiro-Barcelona), Tesis doctoral, Facultad de Geografía e Historia, Universidad de Barcelona, 20I2

VIRUELA, Rafael, «Inmigrantes rumanos en España: aspectos territoriales y procesos de sustitución laboral», Scripta Nova, vol. X, nº 222, I de octubre de 2006 